\title{
THE MEANINGS OF QUALITY OF LIFE: INTERPRETATIVE ANALYSIS BASED ON EXPERIENCES OF PEOPLE IN BURNS REHABILITATION ${ }^{1}$
}

\author{
Maria Cristina Silva Costa ${ }^{2}$ \\ Lídia Aparecida Rossi ${ }^{3}$ \\ Lívia Mara Lopes ${ }^{4}$ \\ Caroline Lopes Cioffi ${ }^{4}$
}

Costa MCS, Rossi LA, Lopes LM, Cioffi CL. The meanings of quality of life: interpretative analysis based on experiences of people in burns rehabilitation. Rev Latino-am Enfermagem 2008 março-abril; 16(2):252-9.

This research aimed to interpret the meanings of quality of life, taking into consideration the meanings attributed by those who have undergone serious burns, their experiences and social/cultural background. We used the ethnographic method based on modern hermeneutics. Nineteen patients with burn sequelae, already discharged from the Burns Unit of the Ribeirão Preto Medical School Clinical Hospital participated in this study, along with their relatives. Participants belong to the working class, are between 18 to 50 years old and have been in rehabilitation for at least a year. Data were collected by direct observation and semi-structured interviews. The analysis was processed through the identification of units of meanings and construction of thematic nucleuses. Patients and relatives reported that quality of life had changed because of physical and psychological limitations caused by the burns. The meanings of quality of life are associated with the performance of social roles and are guided by family, work, normality, autonomy and social integration.

DESCRIPTORS: quality of life; burns; culture; nursing

\section{SIGNIFICADOS PARA LA CALIDAD DE VIDA: ANÁLISIS INTERPRETATIVO FUNDAMENTADO EN LA EXPERIENCIA DE PERSONAS QUEMADAS EM REHABILITACIÓN}

Con el objetivo de interpretar los significados para la calidad de vida, este estudio parte de la atribución dada por personas que sufrieron quemaduras graves, sus experiencias y su contexto sociocultural. El método etnográfico fue utilizado apoyado en la teoría hermenéutica moderna. Participaron del estudio 19 pacientes con secuelas de quemadura y sus familiares, atendidos en la Unidad de Quemados del Hospital de Clínicas de la Facultad de Medicina de Ribeirão Preto. Los sujetos pertenecían al sector popular, con edades entre 18 y 50 años, participantes del programa de rehabilitación por lo menos un año. Los datos recolectados a través de entrevistas semi-estructuradas y observación directa; siendo su análisis realizado a través de la identificación de unidades de significados y construcción de núcleos temáticos. Los pacientes y sus familiares mencionaron cambios en su calidad de vida debidos a sus limitaciones físicas y psíquicas por la quemadura. La calidad de vida asociada al desempeño de los roles sociales fue estructurada en base a los núcleos: familia, trabajo, autonomía, normalidad e integración social.

DESCRIPTORES: calidad de vida; quemaduras; cultura; enfermería

\section{SIGNIFICADOS DE QUALIDADE DE VIDA: ANÁLISE INTERPRETATIVA BASEADA NA EXPERIÊNCIA DE PESSOAS EM REABILITAÇÃO DE QUEIMADURAS}

Com o objetivo de interpretar os significados de qualidade de vida, este estudo considera os sentidos atribuídos por pessoas que sofreram queimaduras graves, suas experiências e contexto sociocultural. Utilizou-se o método etnográfico com apoio teórico da hermenêutica moderna. Participaram 19 pacientes com seqüelas de queimadura, atendidos pela Unidade de Queimados do Hospital das Clínicas da Faculdade de Medicina de Ribeirão Preto, e seus familiares. Pertencentes às classes populares, os sujeitos, com idade entre 18 e 50 anos, integram programa de reabilitação há um ano ou mais. A análise dos dados, coletados por entrevistas semi-estruturadas e observação direta, processou-se pela identificação de unidades de significados e construção de núcleos temáticos. Pacientes e familiares relataram modificações da qualidade de vida introduzidas por limitações físicas e psíquicas provocadas pela queimadura. Qualidade de vida, associada ao desempenho de papéis sociais, estrutura-se em torno dos núcleos: família, trabalho, autonomia, normalidade e integração social.

DESCRITORES: qualidade de vida; queimaduras; cultura; enfermagem

${ }^{1}$ Study funded by FAPESP and CNPq; ${ }^{2}$ Anthropologist, PhD, Faculty, e-mail: mccosta@eerp.usp.br; ${ }^{3}$ RN, Associate Professor; ${ }^{4}$ Nursing undergraduate student. University of São Paulo at Ribeirão Preto, College of Nursing, WHO Collaborating Centre for Nursing Research Development, Brazil 


\section{INTRODUCTION}

Since 1970, a growing interest in quality of life assessment has been observed in the health area, possibly due to increased life expectancy and the survival of people with disabilities or with chronic health conditions. The existence of different ways of conceptualizing quality of life can also be noticed, being a complex and comprehensive concept ${ }^{(1)}$, involving a wide array of dimensions: biological, psychological, social, cultural and environmental.

Studies on quality of life have been conducted within a naturalistic perspective. As such, the scales that evaluate quality of life do not capture its subjectivity, even when they reflect the multidisciplinary nature of the human focus on its domains and focus on the emotional and health status, social interactions, economic status and physical capacity. The same happens regarding the socio-cultural idiosyncrasies of social groups and classes. It cannot be ignored that man is a biological organism, and as such may be an object of study centered on the biologic organism and disease, within the naturalistic perspective. However, the characteristics that make a man a person cannot be ignored and, hence, it is necessary to understand and interpret their motivations, values, believes and what directs the focus towards the cultural dimension. Therefore, studies about the comprehension and interpretation of the meaning of quality of life could complement the studies developed from a naturalistic perspective ${ }^{(1)}$.

Regarding the person who suffered burns and aspects related to quality of life, literature reveals a focus on the process of rehabilitation and adaptation after the trauma and the chronic psychological problems involved in the development of posttraumatic stress, by using instruments to assess the health quality and status, such as the Burn Specific Health Scale ${ }^{(2)}$. Studies that focus on the perspectives of people affected by burns and on the meanings of quality of life, referring to a symbolic dimension, are not listed in literature.

There is a relevant interpretative focus on the approach of quality of life of people afflicted by burns that, stemming from meanings built by the subjects, is directed towards the symbolic dimensions and promotes the social contextualization of the issue ${ }^{(1,3-5)}$. This perception encouraged a focused research, aiming to contribute to the interpretation of the meanings of quality of life, and using the experience of people in the rehabilitation process, as well as the meanings they attribute to this experience, as its empirical data.

The study is based on the assumption that the meanings individually attributed to quality of life articulate with socially-built meanings, reflecting knowledge, beliefs, priorities, practices, social standards and values adopted at a given historical moment and express cultural characteristics of social groups and societies. Therefore, interpreting the meanings of quality of life among people who experienced the burn rehabilitation process requires their identification among individuals, to analytically insert them in the structures of meaning they are integrated in, and which implies considering the collective production of meanings.

Culture, as predominantly conceived by anthropology, is a symbolic universe, or a universe of meanings, a collective construct that universally characterizes human social life. By assuming culture as a "web of meanings" woven by $\operatorname{man}^{(6)}$, the fact that man is an active subject of this process in his social life is highlighted. Also, it can be noticed that the "webs of meaning" created by man are not immutable or static, but are in a social process of constant transmission and change, coming to be in different lifestyles, standards, beliefs, values and habits. More than making cultural heterogeneity among peoples explicit, coexistence is subjacent in such cultural conception, in the same society, of several cultural diversities associated to groups and social classes $^{(7)}$.

Cultural heterogeneity, expressed by different groups, associated to several conditions of existence, including social inequalities, is manifested by means of behaviors and interpretation of events. Within its own cultural specificities, each group has several ways to attribute meaning to everything, to feeling or being sick, quality of life, among others. The social representations of disease and quality of life consequently reflect the playing of roles and social use of the body, in a perspective that emphasizes the interconnection of action and role performance (where the experiences of individuals and social groups inform and direct the role-playing) ${ }^{(7)}$.

In order to contribute to the interpretation of the meanings of quality of life of a group of people in a process of burn rehabilitation, based on their own experiences, conceptions and values, the objectives of this study were: identifying the priorities established 
by the subjects for their lives; delimiting the changes introduced in their lives after the burns and their sequelae; distinguishing the meanings attributed to the experience of burns and its sequelae.

\section{METHODOLOGY}

The research uses the ethnographic method - ethnography being understood as a "dense description", a "description seeking for meanings"(6). This kind of research involves a relation of proximity and intersubjective exchange between the researcher and the subjects, in an ethnographic encounter, so that two distinct symbolic universes can interweave and the subjects' cultural logic of the topics can be unveiled $^{(8)}$. Based on modern hermeneutics, this study refers to the interpretation of meanings of practices and reports by subjects who are in rehabilitation due to serious burns, inserting them in the subjects' cultural context ${ }^{(9)}$.

The subjects were a group of 19 people, of both genders (12 male and 7 female), living in Ribeirão Preto (SP, Brazil). Interviewees were ex-patients selected within the age range of 18 to 50 , who had been admitted to the Burns Unit of the Ribeirão Preto Medical School Hospital das Clínicas, and who had been in rehabilitation for one year or longer and did not show limitations that would impair their participation. The Burns Unit of has eight beds and admits adult and pediatric patients. Among the 44 identified people who fit the inclusion criteria and agreed to participate in the research, 19 were selected, by the delimitation of the number of participants done a posteriori, using the data saturation criterion, i.e., by verifying that the information obtained did not contain any new data. Eleven relatives of the subjects who were present at the time of data collection also took part in the study. All participants agreed to take part in the study by signing the Free and Informed Consent Term, after being properly informed about the research objectives and their participation, about not incurring in any kind of financial, emotional or physical loss, and about having their identities kept anonymous. The research, carried out in 2004-2005, as part of a Theme Project funded by the São Paulo State Research Foundation - FAPESP, was approved in a meeting on November 11, 2002, by the Research Ethics Committee at the Ribeirão Preto Hospital das Clínicas.
The study participants are members of lowerincome social classes, who occupied or occupy subordinate positions in the social hierarchy and experienced forms of social exclusion, revealed by their difficulty in satisfying material existential needs. Although their current social status was not an inclusion criterion in the research, this came to be regarded as relevant information for group definition, probably due to the fact that they are public healthcare service users.

Direct observation and semi-structured interviews were used as techniques, performed at the subjects' households. The interviews were recorded with the authorization of the interviewees and transcribed. The interview script was elaborated to collect: meanings that the subjects attribute to a good quality of life, associated to happiness, satisfaction, achievement and personal success; the elements activated in the construction of self-image; meanings of quality of life; associations of the burns suffered and their sequelae with their current life; comparisons between activities, experiences, pleasures, suffering, feelings, before and after the burn; explanations of the determining factors of the burn; meanings attributed to the trauma suffered and its sequelae.

The meanings acquired constitute the empirical material for the analysis, whose goal is to interpret meanings, and not to be mistaken by "seeing things from the player's viewpoint"(6), and to integrate them in their social base. It is assumed, therefore, that the differentiation between feeling and meaning, where "feelings" are attached to the concrete experience of the subjects, and "meanings" result from the analytic effort of the researcher ${ }^{(6,9)}$.

The process of data analysis covered the following inter-related stages: reading the collected material, identifying and grouping the units of meaning and interpretation by means of central themes. In this process, convergences and divergences of meanings were both considered. A "hermeneutic circle $^{\prime \prime(9)}$ was configured, where the whole and its parts are identified by dialectic interpenetration. To promote this interpenetration, data from each participant was initially focused on. Afterwards, they were related with those of the group of participants. The analysis assured that the data obtained from distinct participants, initially apart, could be interpreted in the context of the whole array of accounts that, in turn, explained the meanings of the parts. 


\section{RESULTS: THE MEANINGS OF QUALITY OF LIFE.}

Trauma is how most subjects define the experience of the burns. The meanings of trauma are usually and predominantly associated with pain, defined as intense and unbearable, but also related to feelings of insecurity, regarding the risk of death, the experience of being an inpatient and the hospital environment. The experience is also highlighted by worries about physical changes, mentioned as deformations, the risks of mobility loss and amputation of the affected limb, and with the possible changes in their day-to-day life (particularly work, leisure and domestic-related limitations).

Responses to trauma, insecurity and worries display a wide range of variations, from overloading with affirmative meanings to denying any meaning to the burn experience. One of the interviewees refers to the experience as a moment to reflect about life and her relationship with her family and friends, attributing the meaning of changing values to it. In this case, even though the experience of the burn is still considered a trauma, it is seen as an "evil that caused some good", entailing a higher valuation of life, health and improvement in the relationship with family and friends, since, before the accident, her life was focused only on work. Another participant, when strictly relating the burn with suffering, says: I asked the doc to turn me off. I'd rather die than live in pain, which was intense.

When meanings were attributed to good life and happiness, the accounts show correspondence with being healthy, having a job, comfort, good family relationships and more time to rest. Highlights associated with satisfaction include: lack of physical impairment, having friends and good family relationships, health, work capacity and material comfort. Highlights associated to personal success include: work, willpower, life improvement, satisfaction of material needs and autonomy. The meanings of good life tied to personal achievements result in: getting things on one's own, not having to depend on anyone; having a job; health, lack of scars, owning a household, satisfying family needs and accepting the limitations caused by the burn.

Most subjects show a highlighted dissatisfaction with their physical appearance altered by the burn sequelae by trying to hide them, due to shame, or to avoid curious inspection and remarks, or by fear of scaring people away, including their own family members. Only one of the study participants affirms not having any qualms about it, and shows it by how she exposes the large scars on her arms. However, she also notices when people are looking curiously, although she reacts differently. She asks people who look at her: Would you like to see it? And she rolls up her sleeves to completely expose her scars.

Other aspects reflect on self-image: work, movement or relationship-related difficulties, with difficulties in family and sexual relationships being highlighted. It results in a new self-image being built after the burn, highlighted by negativity and deprivation, which most commonly affect adult men who are family heads and see the continuity of their social roles impaired.

For most participants, the burn is conceived as a milestone that sets a healthy life apart from an unhealthy life, where they are not able to work like before anymore, cannot leave home, cannot go out, cannot do anything else anymore.

Among men, an impaired exercise of the role of provider and virility associated to sexual prowess is highlighted. Such impairments are shown to have a deep impact on the self-esteem of those who suffer movement-limiting burn sequelae, restricting their freedom and crippling them for work and for the social and sexual performances that were common before the burn.

As to the adoption of new lifestyles after the burn, most report the need to: protect and hide the scars, avoid situations of body exposure; perform massages on the affected areas and use moisturizers.

The results of observation, interviews and reports from family members show that the subjects, with rare exceptions, became less communicative within their social group after the burn, or simply withdrew from social life outside home. Most acknowledge being emotionally more fragile, and some refer to their situation as a constant struggle, or as a barrier. For some, the burn sequelae made them become more aggressive, rude, impatient, nonconforming, angry, depressive or anguished. Most of them display a negative self-image and psychic suffering in their new lifestyle and in their reports.

Two kinds of assessment are highlighted among the subjects in the acceptance process of physical changes due to burning. One is an affirmative assessment, established by comparing the trauma and its sequelae with worse conditions in which other people can be found, or because the burn and its consequences could have been worse, or still, because 
the person, having survived, considers himself/herself victorious. Another evaluation highlights the need to get used to it, meaning that they have to accommodate to an undesired and cumbersome situation.

The most significant attributes associated to quality of life are: maintenance of family and friendship bonds, being healthy, having satisfactory hygiene, being able to work, having moments of leisure with family and satisfying family needs of nourishment, livelihood and comfort.

The compromising of the subject's quality of life, acknowledged by nearly everyone, is conceived in the reports as an obstacle to being able to perform their social roles. They consider that all changes caused by the trauma result in damages to quality of life, due to disadvantages experienced in their daily life, such as: difficulties to find jobs, to adapt to work previously done, or because they cannot work anymore. They also acknowledge as elements that impair their quality of life: time spent to take care of their burn; the need to develop strategies to bring their lives back to normal; physical limitations, represented as disabilities and demanding changes in the routine of daily activities; damage caused in the relationship with family members, particularly when affective and sexual relationships with spouses are considered; inability to perform once-usual leisure activities and/ or with children; loss of autonomy to perform simple activities, which they previously took for granted.

When the burn affected the lower limbs, the damages to quality of life, besides being linked to the aforementioned limitations, are also related to discomfort due to not being able to stand for a long time, because the scar itches, the leg swells or it simply hurts; some of the participants reported that they needed to sit with their leg up high most of the time, to avoid swelling and pain, or to constantly move to relieve itching.

In order to reach a so-called "satisfactory" quality of life, the elements mentioned by subjects of both genders identify with the following capacities: working, moving the limbs, enjoying moments of leisure with the family, having a satisfactory conjugal relationship, presenting oneself socially without worrying about scars, and defining oneself as a healthy person.

In the subjects' conceptions, health-related quality of life is subordinated to mental and physical well-being and to good performance of social roles: being able to satisfy personal and family needs, not feeling pain, not needing treatment and having full capacity to execute their day-to-day activities.

Looking back at the roots of the trauma and its causes, the subjects associate them to both mundane and sacred dimensions. Although some report being struck by the burn due to stubbornness, children's curiosity or accident, in most cases, religion is a crucial element to explain the origin of the trauma. The explanations they report involve several beliefs: punishment or God's will; payback of debts incurred in past lives, or fate. Even though the sacred dimension is not associated to the other topics addressed, religion emerges as an important focus of attributing meaning to the origin of the trauma and to the suffering unleashed by the burn and its sequelae. Therefore, the activation of sacred logic allows for the attribution of meaning to events and suffering that would be unbearable otherwise.

\section{CENTRAL THEMES}

The interpretative analysis was processed with the elaboration of central themes, built according to relevance and meanings the subjects attributed to quality of life, self-image, burn experience and lifestyle before and after trauma. Based on the described results, five central themes were elaborated: work, normality, autonomy, family life and social integration, all of them inter-related.

In the attribution of meanings to quality of life, among men and women, working capacity is highlighted. Therefore, they reveal the fundamental social representation in the urban-industrial capitalist society, in which work is the norm for the definition of a healthy and normal condition, adapted to the human being. Normality, subordinated to working capacity, is then understood as an essential condition for social integration, considered important by the subjects and by society as a whole.

Normality, defined in relation to an external measurement towards the object it is applied to and considered desirable in a determined historical society, is always somewhat attributed to a pre-established norm, not as a universal, natural attribute; it is also a dynamic and controversial concept. The norm refers to the universe of values, implying preference for an order of values, among many possible ones, and rejection of the inverse order (understood as a disorder, domain of a manifestation understood as 
pathologic). Normalization, considering the meaning of the Latin word norm, corresponds to imposing demands on the body, mind or lifestyle, which work at odds with these demands, as put by a given society. Normalizing consequently assumes the meanings of controlling and integrating a determined order ${ }^{(10)}$.

Sociological and anthropological studies highlight the fact that, in urban-industrial capitalist societies, with their economic imperatives subordinate to the for-profit production of goods, one of the most relevant aspects, understood as a healthy and normal condition of the human being, is working capacity. Built as a fundamental norm, a demand imposed on the body, mind and behavior, subordination of normality to work permeates common sense, understood as a cultural system, an interesting way to apprehend and build the world based on day-today experiences ${ }^{(9)}$.

Since the economic dimension takes the role of an important focus of meaning production in modern urban-industrial societies ${ }^{(11)}$, there are many and constant impositions made on their members to perform income-generating activities. Any compromising of working capacity is seen as an anomaly and subject to rehabilitation, so that a socalled normal and healthy state, adapted to the performance of social roles, may be resumed. As such, those who cannot work are seen and see themselves as abnormal ${ }^{(12)}$.

Overall, the meanings attributed to the condition of normality/health - fundamental in the definition of quality of life - bring the subjects to their previous state regarding the burn, associated to working capacity, freedom of movement, keeping a socially-acceptable appearance and health conditions suitable to social and family integration. The burn, conceived as a biographic rupture, comes out as a compromising element of the subjects' health, since it hampers their autonomy and normality. Such perception of loss of normality is related to changes in life after the burn, since living in conditions conceived as normal identifies with the continuity of work and leisure activities, with a healthy physical appearance, full social and family interactions and capacity to move freely.

Lost normality, in the evaluation of the burn as a biographic rupture, represents the crushing of the individuals' self-esteem, freedom and autonomy, as well as whatever they consider to be a life wellintegrated to society. That becomes evident in the association of the burn and its movement-limiting sequelae, observed in married male participants, with damage to autonomy and the loss of the role of provider and of virility. Thus, they show the articulation of the meanings of normality with the performance of gender-based social roles.

When working capacity is prioritized, overseeing normality and social integration, the subjects of the study generally reveal values of the modern urban-industrial society in their worldview. This view, characteristic of modern times, is in turn mixed with traditional values, where personality, family and position in the family hierarchy emerge as relevant values.

The same combination of elements, which ambiguously refers to traditional and modern symbolic ordinations, oversees the conception of work. For the urban-industrial society, it is configured as a producer of economic value; for the study subjects, more than being associated to having a salary and acquiring goods, it is conceived as a moral value, which sustains the honor of the worker-provider of the household. Seen as a unit of income and consumption, the family constitutes the end to which work is directed, and at the same time the way individuals show themselves to society as full citizens.

Besides work, modern society placed expectations on isolated individuals pushing them to the quest for success, happiness and personal achievement. On the one hand, these perspectives are linked to the capacity of acquiring material goods, measured by visible signs of status: in contemporary societies, we are above all consumers. On the other hand, personal success is subordinated to aesthetic standards, as shown by research on the topic ${ }^{(13)}$.

Among the research subjects, it can be observed that normality, connected to working capacity, is also restrained by physical appearance without evidence of rupture of the established standards. They reveal the emphasis placed on being looked at by others, to the critical evaluation of society, with wide repercussions in social integration and self-esteem. They show the correlation of quality of life and established aesthetic standards, which associate physical integrity and an ideal of beauty. As seen in literature, they corroborate it when stating that the burn affects many aspects of a person's life in the world today, and that the individual's appearance, as well as his/her functional capacity, makes reintegration to society difficult ${ }^{(14)}$. 
The body is evaluated, in our society, by its external dimension, according to what is defined as corporal beauty, with the valuation of certain characteristics over others. As shown by studies on the symbolism of the body in our society, it is expected that people are seen as attractive to be successful, while those who stay too far from the standards of attractiveness are expected to be poor and with few opportunities of social ascension ${ }^{(13)}$. The body, more than simply a means of relating with the world, is the individual's means of identification, a way of showing oneself that, when too far away from the aesthetic standards, this poses as an obstacle to social integration $^{(12)}$.

Moreover, there is also a sort of "compensatory logic"(15) in the process of acceptance of physical changes caused by the burn, explained by the comparison with worse situations, the emphasis placed on the ability to endure pain and the elaboration of surviving the burn as a "victory". Such attributions of meaning show the idea of moral compensation, a characteristic of a hierarchical conception of the world. In this interpretation of the burn and its sequelae, these are not seen as signs of inferiority before "normal people" and receive a positive evaluation, becoming hallmarks of moral superiority.

The hierarchical conception of the world highlighted in the activation of "compensatory logic" is similarly revealed when the research participants attribute the source of all their suffering to divine intervention, and bring meanings articulated in the orb of the sacred, which assures a place in the cosmic order to all facts.

Social integration, an important focus of production of meanings of quality of life to which all

\section{REFERENCES}

1. Rosenberg R. Health related quality of life between naturalism and hermeneutic. Soc Sc Med 1995 November; 41(10): 1411-5.

2. Munster A. Measurements of quality of life: then and now. Burns 1999; 25:25-8.

3. Rossi LA, Vila VSC, Zago MMF, Ferreira E. The stigma of burns: perceptions of burned patients' relatives when facing discharge from hospital. Burns 2005 February;31(1):37-44. 4. Minayo MCS, Hartz ZMA, Buss PM. Qualidade de vida e saúde: Um debate necessário. Cien Saúde Coletiva 2000 abril; 5(1):7-18.

5. Koch T. Life quality vs 'quality of life': Assumptions underlying prospective quality of life instruments in health care planning. Soc Sci Med 2000 August; 51(3):419-27. the others converge as necessary conditions, is evidently related to working capacity, having (or regaining) autonomy, inserting oneself in family and in society in a satisfactory way, and to normality. The same importance of social integration is revealed in research on quality of life of Spanish people who suffered burns. The study shows that, even when the burn sequelae do not represent a significant impediment to work or personal care, it is seen as an important problem in social and affective relations and activities in general, and, overall, with regard to emotional aspects $^{(16)}$.

\section{FINAL CONSIDERATIONS}

Family life, social integration, work, normality and autonomy are guiding axes for the attribution of meaning to quality of life among the subjects under study. Seen as important foci for the attribution of meaning to the world order, they permit access to the structures of meaning where their behavior and conceptions are produced and interpreted.

The worldview of the group under study is ambiguously articulated by two rationales - modern and traditional - where evaluations based on economic and pragmatic criteria are combined with others, built on feelings and moral values. This is the cultural context where the meanings of quality of life are built, which is relevant to understand the group and serving as a base for healthcare professionals to work.

Mental suffering cannot be underestimated, nor can possible damage caused to self-image and social integration, besides pains, physical discomfort and functional limitations brought about by the trauma.
6. Geertz C. The interpretation of cultures. New York (NY): Basic Books; 1977.

7. Durham ER. A Dinâmica da Cultura: Ensaios de Antropologia. São Paulo (SP): Cosac Naify; 2004.

8. Costa MCS. Intersubjetividade e historicidade: Contribuições da moderna hermenêutica à pesquisa etnográfica. Rev Latino-am Enfermagem 2002 maio-junho; 10(3):372-82.

9. Geertz C. O Saber Local. Novos ensaios em antropologia interpretativa. Petrópolis: Vozes; 1999.

10. Canguilhem G. O Normal e o patológico. Rio de Janeiro: Forense Universitária; 2002.

11. Sahlins M. Cultura e razão prática. Rio de Janeiro: Zahar; 1979. 12. Ferreira J. O Corpo Sígnico. In Alves PC, Minayo MCS, organizadores. Saúde e doença: Um olhar antropológico. Rio de Janeiro (RJ): Fiocruz; 1998. 
13. Queiroz RS, organizador. O corpo do brasileiro: Estudos de estética e beleza. São Paulo (SP): SENAC; 2000.

14. Gilboa D. Long-term psychosocial adjustment after burn injury. Burns 2001 June; 27:335-41.

15. Da Matta R. Conta de mentiroso: Sete ensaios de antropologia brasileira. Rio de Janeiro (RJ): Rocco; 1993.

16. Salvador-Sanz JF, Sanchez-Paya J, Rodriguez-Marin J. Quality of life of the burn patient. Burns 1999 November; 25(7):593-8. 